\title{
The phenolic mycoside of Mycobacterium ulcerans: structure and taxonomic implications
}

\author{
Mamadou Daffé, ${ }^{*}{ }^{*}$ AnNe VARnerot ${ }^{2}$ and VÉronique Vincent LÉVy-FrÉbault ${ }^{2}$ \\ ${ }^{1}$ Centre de Recherche de Biochimie et de Génétique Cellulaires du CNRS, 118 route de Narbonne, 31062 Toulouse \\ Cédex, France. \\ ${ }^{2}$ Unité de la Tuberculose et des Mycobactéries, Institut Pasteur, 25 rue du Docteur Roux, 75724 Paris Cédex 15, France.
}

(Received 20 June 1991; revised 15 August 1991; accepted 11 September 1991)

\begin{abstract}
Mycobacterium ulcerans and some pathogenic mycobacterial species elaborate wax A consisting of related longchain $\beta$-diol components (phthiocerol and related compounds) esterified by multimethyl-branched fatty acids. With the exception of $M$. ulcerans, wax A-containing mycobacteria also synthesize glycosylated phenol phthiocerol diester and related compounds: the so-called phenolic mycosides. In a deliberate effort to characterize this latter class of compounds in M. ulcerans, 20 strains were examined. Phenolic mycosides were found in two strains. Application of chemical analyses, including one- and two-dimensional NMR spectroscopy, allowed the structural elucidation of glycolipids identified as 3-O-methyl- $\alpha$-L-rhamnosyl phenol phthiocerol diphthioceranate and related compounds which correspond to mycoside G, previously characterized in $M$. marinum by other investigators. As phenolic mycosides are highly species-specific molecules, this finding stresses the close phylogenetic link between $M$. marinum and $M$. ulcerans. Incidentally, a survey of the mycolate content of $\boldsymbol{M}$. ulcerans showed that methoxymycolate could not be detected in three strains.
\end{abstract}

\section{Introduction}

Mycobacterium ulcerans is the aetiologic agent of an indolent, necrotizing skin disease. A review (Portaels, 1989) has been devoted to the epidemiology of this infection which is endemic in some defined areas of the southern hemisphere (Hayman, 1984). Strains are characterized by slow growth occurring only at $30^{\circ} \mathrm{C}$ and which may require several months even after subculture. Consequently, classical identification is difficult to perform and chemotaxonomic markers are of high value. $M$. ulcerans synthesizes $\alpha$-, methoxy-, and ketomycolates, like several other mycobacterial species including tubercle bacilli, $\boldsymbol{M}$. marinum, $\boldsymbol{M}$. kansasii and $\boldsymbol{M}$. gastri (Daffé et al., 1983, 1991b; Minnikin et al., 1984a). Moreover, $M$. ulcerans, M. leprae (Daffé \& Lanéelle, 1988 ) and the limited set of the above-mentioned species elaborate the so-called wax A composed of long chain $\beta$-diols (the phthiocerol family: Fig. 1, compounds I-III), with each mole of $\beta$-diol being esterified by two moles of multimethyl-branched fatty acids (Fig. 1, compound VII). An aromatic derivative, structurally related to phthiodiolone, called phenol phthiodiolone (Fig. 1, compound VI) has also been characterized in M. ulcerans (Daffé et al., 1984). The distribution of all these related lipids (phthiocerol, phthiodiolone, phenol phthiocerol and phenol phthiodiolone), as well as the nature of the fatty acids esterifying them, has been reviewed recently (Daffé \& Lanéelle, 1988). With the exception of $\boldsymbol{M}$. ulcerans, glycosylated phenol phthiocerol diester and related compounds, called phenolic mycosides, have been found in species able to synthesize wax A (Daffé \& Lanéelle, 1988). Phenolic mycosides represent a class of mycobacterial antigens on which ELISA serodiagnostic tests rely (Brett et al., 1983; Cho et al., 1983; Martin-Casabona et al., 1989; Torgal-Garcia et al., 1988; Young \& Buchanan, 1983).

However, wax A, as well as phenolic mycosides, are not present in all strains of a given species (Daffé \& Lanéelle, 1988; Daffé et al., $1991 a$; Lévy-Frébault \& Varnerot, 1989). In the present study we investigate the distribution of some specific lipids, including mycolic acids and phthiocerol derivatives, in order to ascertain chemotaxonomic markers helpful for the identification of $M$. ulcerans and to undertake a deliberate search for phenolic mycosides. We were able to detect the presence of large amounts of an apolar phenolic mycoside in two $M$. ulcerans strains and have elucidated the structure in this study. 


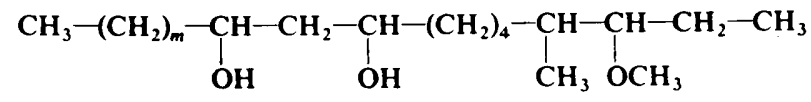

Phthiocerol A (I)

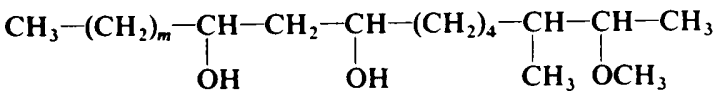

Phthiocerol B (II)

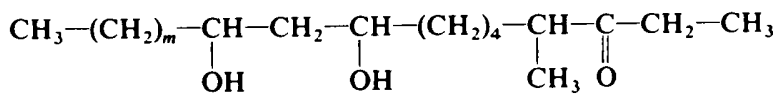

Phthiodiolone (III)

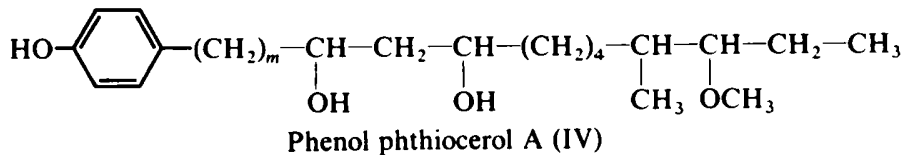

Phenol phthiocerol A (IV)
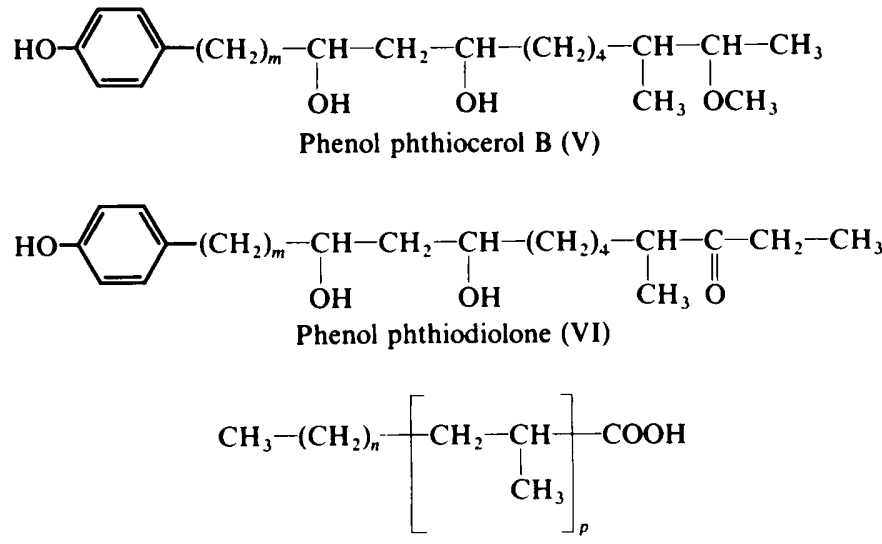

Polymethyl-branched fatty acids (VII)

Fig. 1. Formulae of mycobacterial phthiocerol, phenol phthiocerol and related compounds, and multimethyl-branched fatty acids. I-III, $m=14-20$; IV-VI, $m=16-22$; VII, $n=12-20$ and $p=3-4$.

\section{Methods}

Strains studied. Twenty $M$. ulcerans strains were included in the study (Table 1). Representatives of other mycobacterial species were also used: $M$. marinum CIPT 14012 0003, $M$. avium CIPT 140310002 (ATCC 25291), M. gastri CIPT 140340001 (ATCC 15754) and $M$. bovis BCG CIPT 140040001 (strain Pasteur).

Growth conditions. M. ulcerans strains were cultivated on Löwenstein-Jensen medium (Diagnostics Pasteur) or on a biphasic medium consisting of a Löwenstein-Jensen solid phase $\left(75 \mathrm{~cm}^{2}\right.$ surface area) and $7 \mathrm{H} 9$ Middlebrook liquid phase $(10 \mathrm{ml})$ (B. Carbonnelle, personal communication). Medium was distributed in plastic screw-capped flasks. After inoculation, flasks were incubated at $30^{\circ} \mathrm{C}$ in an upright position and rolled once, once a day during the period of incubation. Serial subcultures performed in these conditions allowed us to obtain a substantial cell yield after a 3-4 week incubation period. $M$. marinum was grown on Sauton's medium (Sauton, 1912) at $33^{\circ} \mathrm{C}$ for 4 weeks and its specific phenolic mycoside $\mathrm{G}$ was isolated in the same way as that of $M$. ulcerans (see below). Other strains used for controls for phenolic mycoside detection were cultivated on Löwenstein-Jensen medium.

Mycolic acid and other fatty acid analyses. Extraction, purification and derivatization as well as TLC were performed as previously described (Daffé et al., 1983). Briefly, cells were scraped from
Löwenstein-Jensen medium and saponified in $5 \%(\mathrm{w} / \mathrm{v}) \mathrm{KOH}$ in 2methoxyethanol (methylcellosolve) containing $12 \%(\mathrm{v} / \mathrm{v}) \mathrm{H}_{2} \mathrm{O}$, at $110^{\circ} \mathrm{C}$ for $8 \mathrm{~h}$ to ensure complete hydrolysis of sterically hindered ester groups. After acidification with $\mathrm{H}_{2} \mathrm{SO}_{4}$, the solution was partitioned with diethyl ether. The ether phase was washed five times with distilled water and then dried. Fatty acids in extracts were esterified using a diethyl ether solution of diazomethane, freshly prepared from $\mathrm{N}$ methyl- $N$-nitroso- $p$-toluene sulphonamide (Diazogen; Janssen Chimica, Beerse, Belgium), for $15 \mathrm{~min}$ at room temperature. The solution was then dried under nitrogen and the lipids were redissolved in diethyl ether. TLC was performed in duplicate on K6 silica gel (Whatman). One plate was eluted with dichloromethane and the other plate was developed with a mixture of light petroleum ether (b.p. $50^{\circ} \mathrm{C}$ ) and diethyl ether $(9: 1, v / v)$ three times. GC was performed on fatty acid methyl esters using a Delsi 330 instrument equipped with a flame ionization detector and a $\frac{1}{8}$ in. $\times 3 \mathrm{~m}$ nickel column, filled with Chromosorb W coated with $5 \% \mathrm{OV}-1$. Nitrogen was used as the carrier gas with a flow rate of $30 \mathrm{ml} \mathrm{min}^{-1}$. The temperature gradient of the column was programmed from 130 to $280^{\circ} \mathrm{C}$ at a rate of $5^{\circ} \mathrm{C} \mathrm{min}-1$. Multimethyl-branched fatty acid and butyl glycoside derivatives were identified by GC using a Girdel chromatograph (model G30) equipped with a fused silica capillary column $(25 \mathrm{~m} \times 0.22 \mathrm{~mm}$ internal diam.) containing WCOT OV-1 $(0.3 \mu \mathrm{m}$ film thickness, spiral, Dijon, France). A temperature gradient of $150-290^{\circ} \mathrm{C}$ at $2{ }^{\circ} \mathrm{C} \mathrm{min}-1$ was used. 
Table 1. Strains of $M$. ulcerans

\begin{tabular}{|c|c|c|c|c|}
\hline Strain number* & Sourcet & $\begin{array}{c}\text { Mycolate } \\
\text { typeł }\end{array}$ & $\begin{array}{c}\text { Phthiodiolone } \\
\text { derivative }\end{array}$ & Mycoside G\| \\
\hline CIPT 1090001 (ATCC 19423) & G. Buckle, Australia & I, III, IV & + & - \\
\hline CIPT 1090002 & P. Lavalle, Mexico & I, IV & - & - \\
\hline CIPT 1090003 (HB 1673) & Dr Tarskis, Congo & I, III, IV & - & - \\
\hline CIPT 1090004 & Dr Darasse & I, III, IV & + & - \\
\hline CIPT 1090005 (SP 151) & S. Pattyn, Zaire & I, III, IV & - & - \\
\hline CIPT 1090006 (SP 273) & S. Pattyn, Zaire & I, III, IV & + & - \\
\hline CIPT 1090007 (SP 286) & S. Pattyn, Zaire & I, III, IV & - & - \\
\hline CIPT 1090008 (SP 498) & S. Pattyn, Zaire & I, IV & - & - \\
\hline CIPT 1090009 (HB 3434) & M. Huet, Cameroon & I, III, IV & + & - \\
\hline CIPT 1090010 (HB 3435) & M. Huet, Cameroon & I, III, IV & + & - \\
\hline CIPT 1090011 (HB 3436) & M. Huet, Cameroon & I, IV & + & - \\
\hline CIPT 1090012 (HB 4145) & M. Huet, Cameroon & I, III, IV & + & - \\
\hline CIPT 1090013 (HB 4834) & M. Huet, Cameroon & I, III, IV & + & - \\
\hline CIPT 1090014 (HB 5091) & Dr Ménard, Cameroon & I, III, IV & + & - \\
\hline CIPT 1090015 & J. Grosset, France & I, III, IV & - & - \\
\hline CIPT 1090016 (CIP 812023) & This laboratory & I, III, IV & + & - \\
\hline CIPT 1090018 (CIP 811479) & Guyana & I, III, IV & + & + \\
\hline CIPT 1090019 (ATCC 33728) & M. Tsukamura, Japan & I, III, IV & - & - \\
\hline CIPT 1090020 (CIP 841477) & Y. Pérol, France & I, III, IV & + & - \\
\hline CIPT 1090021 (CIP 890922) & B. Carbonelle, France & I, III, IV & - & + \\
\hline
\end{tabular}

- CIPT, Collection Institut Pasteur Tuberculose, Paris, France; ATCC, American Type Culture Collection, Rockville, MA, USA; HB, H. Boisvert (Paris, France); SP, S. Pattyn (Antwerp, Belgium); CIP, Collection Institut Pasteur, Paris, France.

$\dagger$ The donor of the strain is followed by the country of isolation. The country of isolation of strain CIPT 1090004 is not known.

$\ddagger$ Mycolate types I, III and IV refer to diunsaturated- $(\alpha)$, methoxy- and ketomycolates, respectively.

$\S$ Phthiodiolone and phenol phthiodiolone diesters occur together. Some strains $(+)$ accumulate phthiocerol derivatives in addition to the phthiodiolone diester.

$\|(+)$ indicates detection of a mycoside G-like glycolipid by TLC.

Extraction, detection and purification of the glycolipids. Bacteria were extracted with $\mathrm{CHCl}_{3} / \mathrm{CH}_{3} \mathrm{OH}(2: 1, \mathrm{v} / \mathrm{v})$ at room temperature for 1 week; lipid extracts were spotted onto HP-K high performance silica gel TLC plates (Whatman) and eluted with $\mathrm{CHCl}_{3} / \mathrm{CH}_{3} \mathrm{OH}(9: 1, \mathrm{v} / \mathrm{v})$. Glycolipids were detected by spraying with $0.2 \%(\mathrm{w} / \mathrm{v})$ anthrone in concentrated $\mathrm{H}_{2} \mathrm{SO}_{4}$ followed by heating at $110^{\circ} \mathrm{C}$.

For purification purposes, pooled extracts were dried, dissolved in $\mathrm{CHCl}_{3}$ and applied to a Florisil $(60 / 100 \mathrm{mesh})$ column $(55 \times 21 \mathrm{~cm})$ and elutions were done with $\mathrm{CHCl}_{3}$ and $\mathrm{CHCl}_{3}$ containing 2, 5, 20 and $50 \%$ (v/v) $\mathrm{CH}_{3} \mathrm{OH}$. The collected fractions $(50 \mathrm{ml})$ were dried and analysed by TLC. Final purification of the glycolipid was achieved by preparative TLC using $\mathrm{CHCl}_{3} / \mathrm{CH}_{3} \mathrm{OH}(95: 5, \mathrm{v} / \mathrm{v})$ as the developing solvent.

Miscellaneous analytical techniques. Alkaline hydrolysis of the glycolipid was performed as previously described (Daffé et al., 1983).

Acid hydrolysis was performed with $2 \mathrm{M}-\mathrm{CF}_{3} \mathrm{COOH}$ for $4 \mathrm{~h}$ at $110^{\circ} \mathrm{C}$; the sugars were demethylated (Bonner et al., 1960) and the retention times on GC analysis of the trimethylsilyl derivatives of their (-)-2-butyl-glycosides were compared to that of (-)-2-butyl-Lrhamnoside and (-)-2-butyl-D-rhamnoside (Gerwig et al., 1978).

NMR spectra were obtained in $\mathrm{CDCl}_{3}$ with a Bruker AM 300 WB instrument at $25^{\circ} \mathrm{C}$. The two-dimensional nuclear Overhauser effect spectroscopy (NOESY) experiment was conducted as described elsewhere (Daffé \& Servin, 1989).

IR spectra were recorded on a Perkin-Elmer instrument model 1600 series FTIR.

Optical rotation was determined in $\mathrm{CHCl}_{3}$ solution (dried over $\mathrm{CaCl}_{2}$ ) with a Perkin-Elmer spectropolarimeter model 241 in a temperature controlled cell $\left(20^{\circ} \mathrm{C}\right)$.

\section{Results}

\section{Mycolic acid and fatty acid derivative profiles}

Previous studies, using only a few strains, showed that $M$. ulcerans synthesizes three types of mycolates, namely diunsaturated- (type I), methoxy- (type III) and ketomycolates (type IV) (Daffé et al., 1983, 1991 b). In order to ascertain the chemotaxonomic significance of this mycolic acid pattern, 20 strains were analysed for their mycolate content. As shown in Table 1, all the strains did not present the same mycolic acid profile. Strains CIPT 1090002,1090008 and 1090011 did not accumulate methoxymycolate in sufficient quantity to be detected on TLC plates (Table 1). This feature was not related to the geographical source, as these strains were from Mexico, Zaire and Cameroon, respectively. Fatty acid methyl esters were then examined by GC for the presence of specific chemotaxonomic markers of $\boldsymbol{M}$. ulcerans. The comparative study revealed, in all strains, the presence of a high content of the characteristic $\mathrm{C}_{27}$ phthioceranate methyl ester which represented up to $40 \%$ of the total fatty acid derivatives detectable, a specific feature of $M$. ulcerans (Daffé et al., 1984). 


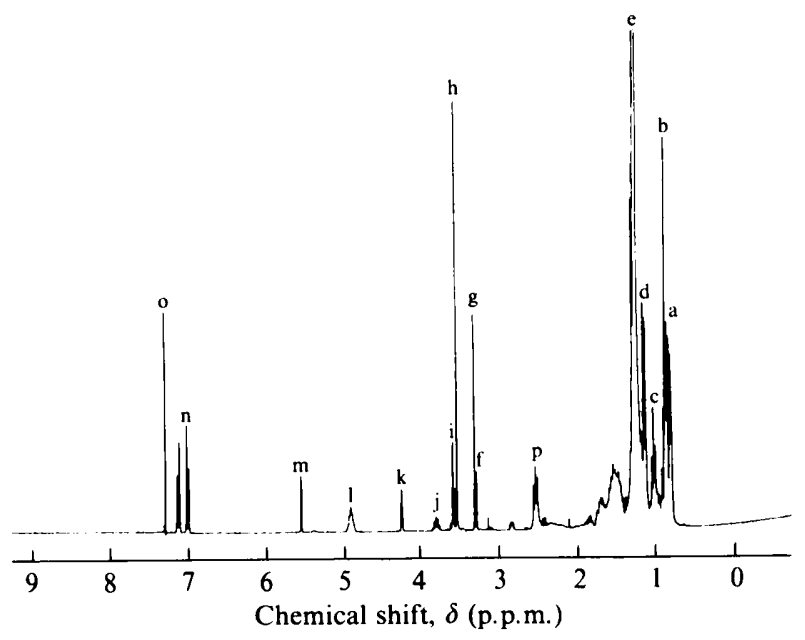

Fig. 2. ${ }^{1} \mathrm{H}-\mathrm{NMR}$ spectrum of the phenolic mycoside of $M$. ulcerans $\left(300 \mathrm{MHz}, \mathrm{CDCl}_{3}\right)$. The labelled resonances correspond to those of protons marked in Fig. 3 except for resonances c $\left(\mathrm{CH}_{3}-\mathrm{CH}_{2}-\mathrm{CO}-\right.$ in phenol phthiodiolone), $\mathrm{f}\left(\mathrm{CH}_{3} \mathrm{O}-\mathrm{CH}-\mathrm{CH}_{3}\right.$ in phenol phthiocerol B) and $\mathrm{o}\left(\mathrm{CHCl}_{3}\right)$.

\section{Detection and preliminary characterization of the phenolic mycoside}

In the crude lipid extracts of two strains of $M$. ulcerans (CIPT 1090018 and 1090021 ), a major glycolipd was detected by TLC. It shared the same chromatographic properties with the two monoglycosyl phenol phthiocerol diesters, namely phenolic mycosides $B$ and $G$ isolated from $M$. bovis and $M$. marinum, respectively, but was clearly different from multiglycosylated phenolic mycosides (Daffé et al., 1987). The optical rotation of the purified glycolipid was found to be $-16^{\circ}\left(\mathrm{CHCl}_{3}\right.$, $c=0.9$ ), a value close to those previously found for mycosides B and G (Daffé et al., 1987). The IR spectrum of the glycolipid was identical to those previously published for phenolic mycosides A, B and G (Gastambide-Odier \& Sarda, 1970; McLennan et al., 1961; Navalkar $e t$ al., 1965) and indicated the occurrence of a phenolic group (absorption bands at 1615, 1535 and $825 \mathrm{~cm}^{-1}$ ).

\section{Carbohydrate constituent of the glycolipid}

The presence in the ${ }^{1} \mathrm{H}-\mathrm{NMR}$ spectrum (Fig. 2) of the glycolipid isolated from $M$. ulcerans of only one signal $(m)$ assignable to the resonance of an anomeric proton $(\delta$ 5.52 p.p.m., 1H) indicated a monoglycosyl structure. In addition to the singlet due to the presence of the methoxyl group of phenolphthiocerol A (compound IV, Fig. 1) at $\delta 3.32$ p.p.m. (signal g, Fig. 2), a second singlet was observed at $\delta 3.54$ p.p.m. (signal h) assignable to the resonance of a methoxyl group located on the sugar
Table 2. Analysis of ${ }^{\prime} H$-NMR data for native and peracetylated derivatives of the monoglycosyl phenol phthiocerol diester of M. ulcerans and M. marinum (mycoside G)

\begin{tabular}{cccc}
\hline \hline & \multicolumn{2}{c}{$\begin{array}{c}\text { Chemical shift, } \\
\delta \text { (p.p.m.) }\end{array}$} & \\
\cline { 2 - 3 } Sugar ring proton & Native & Peracetylated & $\begin{array}{c}\text { Coupling constant } \\
\text { (Hz) }\end{array}$ \\
\hline H-1 & 5.52 & 5.42 & $J_{1 \cdot 2}=1.8$ \\
H-2 & 4.25 & 5.49 & $J_{2 \cdot 3}=3.9$ \\
H-3 & 3.60 & 3.80 & $J_{3 \cdot 4}=10$ \\
H-4 & 3.57 & 5.04 & $J_{4 \cdot 5}=10$ \\
H-5 & 3.82 & 3.95 & $J_{5 \cdot 6}=6.3$ \\
H-6 & 1.38 & 1.17 & - \\
\hline \hline
\end{tabular}

residue. When the resonances of the different sugar protons were assigned (Table 2) it was easy to identify the glycosyl unit as rhamnosyl because of the coupling constant values (Haverkamp et al., 1975). The configuration of the rhamnosyl unit was determined by NOESY which revealed an unambiguous space connectivity between the $\mathrm{H}-1$ and $\mathrm{H}-2$ resonances but not between those of $\mathrm{H}-1$ and $\mathrm{H}-3$ or $\mathrm{H}-5$ (data not shown), establishing an $\alpha$ configuration (Yu et al., 1986). The anomeric proton also showed a space connectivity with the phenyl protons. The location of the methoxyl group was deduced from the same experiment showing a connectivity between the resonance of $\mathrm{H}-2$ and that of the methoxyl protons at $\delta 3.54$ p.p.m (data not shown), thus locating the methoxyl group at position 3 of the sugar residue. These data were confirmed by comparing the spectrum shown in Fig. 2 with those of mycosides B and $\mathrm{G}$ (2-O- and 3-O-methyl rhamnosyl phenol phthiocerol diesters, respectively). The spectrum of mycoside G, but not of mycoside B (Daffé et al., 1988), was found to be superimposable on that shown in Fig. 2. The ${ }^{13} \mathrm{C}$ spectrum of mycoside $\mathrm{G}$ allowed the assignment of an $\alpha$ configuration to the rhamnosyl unit $\left[J_{\mathrm{C} \cdot \mathrm{H}}=168 \mathrm{~Hz}\right.$ (Kasai et al., 1979)] and confirmed the location of the methoxyl group at position 3 ( $\delta 81$ p.p.m.; Haverkamp $e t$ al., 1975). Analysis of the ${ }^{1} \mathrm{H}-\mathrm{NMR}$ of the peracetylated glycolipid (Table 2) also confirmed the $\alpha$ configuration of the rhamnosyl unit: $\delta_{\mathrm{H}-5}>4.7$ p.p.m., $\delta_{\mathrm{H}-6}<1.2$ p.p.m., (Laffite et al., 1978) and the location of the methoxyl group at position 3 (not shifted). The absolute configuration of the rhamnosyl units was determined after demethylation followed by butanolysis of the sugar constituent of both glycolipids isolated from $M$. ulcerans and $M$. marinum (mycoside G). L-R hamnoside was identified in both glycolipid derivatives as the sugar co-chromatographed with derivatives of L-rhamnose but not Drhamnose on GC. This finding is in agreement with the previous results on mycoside G (Ville \& GastambideOdier, 1970). 


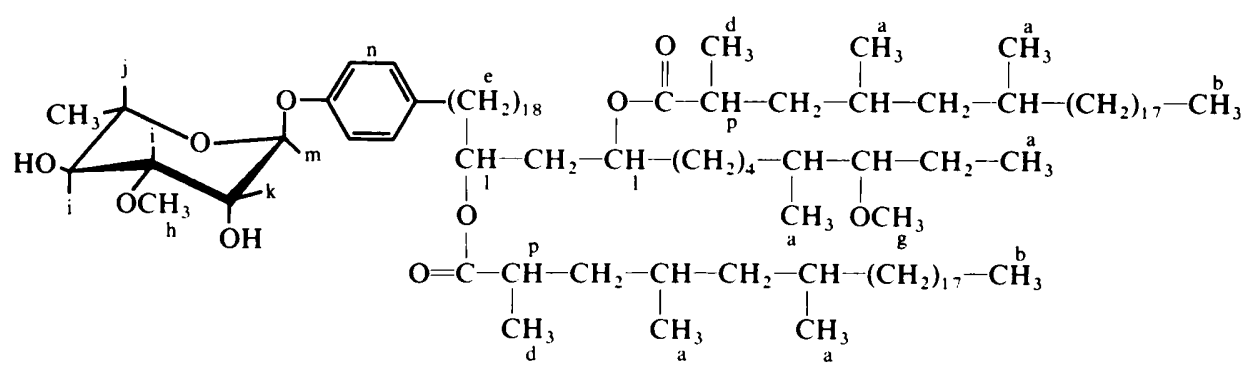

Fig. 3. Proposed structure for the major constituent of the phenolic mycoside of $M$. ulcerans : 3-O-methyl- $\alpha$-L-rhamnosyl phenol phthiocerol diester. The resonances of protons labelled a-n are shown in Fig. 2.

\section{Aglycone moiety of the glycolipid}

The structure of the phenol phthiodiolone of $M$. ulcerans has been established previously (Daffé et al., 1984). Analysis of the ${ }^{1} \mathrm{H}$-NMR spectrum confirmed the presence of an aromatic group $(\delta 6 \cdot 98-7 \cdot 10$ p.p.m., signal n, Fig. 2) and of multimethyl-branched fatty acyl substituents ( $\delta 1 \cdot 14$ p.p.m., signal d, Fig. 2$)$ esterifying a $\beta$-glycol ( $\delta 4.89$ p.p.m., signal 1, Fig. 2$)$. The chemical shift observed for the latter signal was significantly downfield from that ( $\delta 4.83$ p.p.m.) recorded for other phenolic mycosides isolated from $M$. tuberculosis and $M$. bovis (Daffé et al., 1987, 1988) but was similar to that of mycoside G (Dobson et al., 1990). This effect is related to the erythro configuration in the $\beta$-glycol of wax $A$ and phenolic compounds of $\boldsymbol{M}$. marinum and $\boldsymbol{M}$. ulcerans as compared to the threo configuration found in those of $M$. tuberculosis and M. bovis (Besra et al., 1989, 1990).

The presence of a singlet assignable to a methoxyl group at $\delta 3.32$ p.p.m. (1.5H, signal g, Fig. 2) indicated the presence of phenol phthiocerol A (compound IV, Fig. 1). Another singlet at $\delta 3.29$ p.p.m. $(0 \cdot 5 \mathrm{H}$, signal f, Fig. 2$)$ was assigned to the resonance of the methoxyl group of phenol phthiocerol B (compound V, Fig. 1). The intensity of the resonances (signals $\mathrm{g}+\mathrm{f}=2 \mathrm{H}$ ) due to the two phenol phthiocerol derivatives suggested that twothirds of the native mycoside contained phenol phthiocerol moieties. Thus, it appeared likely that the remaining one-third of the native mycoside would contain phenol phthiodiolone diester as its aglycone moiety. The presence of a triplet at $\delta 1.05$ p.p.m. (signal c, Fig. 2) attributable to the terminal methyl group of the phenol phthiodiolone derivative (Daffé \& Servin, 1989; Dobson et al., 1990; Minnikin \& Polgar, 1967) confirmed the above hypothesis. The aglycone moiety appeared then to consist of phenol phthiocerols A, B and phenol phthiodiolone derivatives in a ratio $3: 1: 2$ respectively.

By co-chromatography, using a capillary column and authentic standards, the fatty acyl substituents of the glycolipids of M. ulcerans and M. marinum were found to be mainly 2,4.6-trimethyl tetracosanoyl; small amounts of lower and higher homologues were also present. These fatty acyl derivatives were previously demonstrated to belong to the phthioceranic series in both organisms (Daffé, 1991; Daffé \& Lanéelle, 1988; Daffé et al., 1984) in contrast to those found in wax $A$ and phenolic mycosides of $M$. tuberculosis and other wax A-containing mycobacterial species (Daffé \& Lanéelle, 1988).

Based on the data presented in this paper, the structure shown in Fig. 3 can be proposed for the major component of the phenolic mycoside of $M$. ulcerans. It corresponds also to that of mycoside G of M. marinum, (Dobson et al., 1990; Villé \& Gastambide-Odier, 1970).

\section{Discussion}

As the classical identification of $\boldsymbol{M}$. ulcerans is hampered by the very slow growth of the organisms, we looked for specific chemotaxonomic markers: mycolates, multimethyl-branched fatty acids and their natural forms (wax A and phenolic mycosides).

Previous studies showed that mycolates are a highly reproducible feature within a species (Daffé et al., 1983; Lévy-Frébault et al., 1983, 1986; Luquin et al., 1991; Minnikin et al., 1984a). Previously, when a mycolate profile has differed from that of the type strain, it has usually indicated a misidentification or a mixed culture (Lévy-Frébault et al., 1986, 1987). The unique exception described so far is the case of some of the $M$. bovis BCG strains. It has been shown that Pasteur, Glaxo, Prague, Danish and Chinese BCG strains do not contain methoxymycolates (Daffé et al., 1983; Minnikin et al., $1984 b$ ). Strains of $M$. ulcerans also exhibit variability in methoxymycolate content, as demonstrated in the present study. A possible explanation of this may reside in the postulated biosynthetic relationship between ketoand methoxymycolates, the latter being derived from the former (Minnikin, 1982). 
The fatty acids esterifying wax $A$ and phenolic mycosides can be easily detected by GC and may consequently represent a reliable chemotaxonomic marker for identification of $M$. ulcerans. These fatty acids were previously demonstrated to belong to the phthioceranic series like those from $M$. marinum in contrast to those found in all other wax A-containing mycobacterial species which belong to the mycocerosic series (Daffé \& Lanéelle, 1988), the data stressing an obvious analogy between the fatty acid biosynthesis of $M$. ulcerans and $M$. marinum.

The present study clearly demonstrates that $M$. ulcerans may elaborate phenolic mycosides, the structures of which correspond to those of mycoside $G$ of $\boldsymbol{M}$. marinum (Dobson et al., 1990; Villé \& GastambideOdier, 1970). Only two of the $M$. ulcerans strains, out of the 20 included in the study, revealed the presence of mycoside G. This observation confirms the earlier finding showing that phenolic glycolipids are not reliable markers as they were not found in all the strains of a given species (Daffé \& Lanéelle, 1988). For instance, although the presence of specific phenolic mycosides of $M$. bovis and $M$. tuberculosis was typical for field isolates (Chatterjee et al., 1989; Daffé et al., 1989), the type strain of $M$. bovis does not reveal any mycoside B (Daffé \& Lanéelle, 1988); similarly some $M$. tuberculosis strains do not accumulate detectable amounts of PGL-Tb1 (Daffé \& Lanéelle, 1988; Daffé et al., 1991a). Nevertheless, the presence of identical phenolic mycosides in different species may indicate close phylogenetic relatedness. For example, the two species $M$. tuberculosis and $M$. bovis are both able to synthesize identical mono- and diglycosyl phenolic mycosides (Daffé et al., 1988, $1991 a$; Chatterjee et al., 1989; Vercellone \& Puzo, 1989) and DNA/DNA hybridization studies demonstrated that these two taxa belong to a unique genomic group (Baess, 1979). Similarly, M. kansasii and M. gastri accumulate the same phenolic mycosides (Gilleron et al., 1990; Papa et al., 1987; Vercellone et al., 1988) and were found to be indistinguishable according to their rRNA sequences (Rogall et al., 1990) and their fatty acid content (Daffé et al., 1983). Classical identification methods, however, easily differentiate $\boldsymbol{M}$. kansasii, a potential pathogen frequently isolated in clinical samples, from $M$. gastri, a non-pathogenic species (Wayne \& Kubica, 1986). Consequently, although phenolic mycosides may not always be expressed, when they are, they may show a phylogenetic relationship in close agreement with genetic studies for taxa differentiated by classical identification methods and with distinct pathogenic behaviour. M. marinum, a rapidly-growing photochromogenic species, and $M$. ulcerans, a slowly-growing non-chromogenic species, are easily differentiated by cultural and biochemical tests as well by clinical presentation of the lesions they induce.
$M$. marinum gives cutaneous granuloma, usually selflimiting and $\boldsymbol{M}$. ulcerans produces invasive skin ulcers. Nevertheless, the following characteristics are shared by $M$. marinum and $M$. ulcerans: (i) identical types and subtypes of mycolic acids (Daffé et al., 1983, 1991 b); (ii) the stereochemistry of both the methyl-branched- and the $\beta$-glycol chiral centres occurring in wax $A$ and related phenolic analogues, opposite to those of the other mycobacterial species (Besra et al., 1989, 1990; Daffé, 1991; Daffé \& Lanéelle, 1988; Daffé et al., 1984); and (iii) the identical structure of their phenolic glycolipid. These features stress the close relationship between the two species. In support of this concept is the high genomic relatedness $(86 \%)$ by spectrophotometric assay in DNA/DNA hybridization studies (Imaeda et al., 1988). Further genomic studies will be required to establish the phylogenetic relationship between the different variants of $M$. ulcerans on the one hand and the $M$. marinum strains on the other.

\section{References}

BAESS, I. (1979). Deoxyribonucleic acid relatedness among species of slow-growing mycobacteria. Acta Pathologica et Microbiologica Scandinavica 87, 221-226.

Besra, G. S., Mallet, A. I., Minnikin, D. E. \& Ridell, M. (1989). New members of the phthiocerol and phenol phthiocerol families from Mycobacterium marinum. Journal of the Chemical Society Chemical Communications 1451-1452.

Besra, G. S., Minnikin, D. E., Sharif, A. \& Stanford, J. L. (1990). Characteristic new members of the phthiocerol and phenol phthiocerol families from Mycobacterium ulcerans. FEMS Microbiology Letters 66, 11-14.

Brett, S. J., Draper, P., Payne, S. N. \& Rees, R. J. W. (1983). Serological activity of a characteristic phenolic glycolipid from Mycobacterium leprae in sera from patients with leprosy and tuberculosis. Clinical and Experimental Immunology 52, 271-279.

BoNNER, T. G., Bourne, E. J. \& MCNAlLy, S. (1960). Dealkylation and deacylation of carbohydrate derivatives with boron trichloride and boron tribromide. Journal of the Chemical Society 2929-2934.

Chatterjee, D., Bozic, C. M., Knisley, C., Cho, S.-N. \& Brennan, P. J. (1989). Phenolic glycolipids of Mycobacterium bovis: new structures and synthesis of a corresponding seroreactive neoglycoprotein. Infection and Immunity 57, 322-330.

Cho, S. N., Yanagihara, D. L., Hunter, S. W., Gelber, R. H. \& BRENNAN, P. J. (1983). Serological specificity of phenolic glycolipid I from Mycobacterium leprae and use in serodiagnosis of leprosy. Infection and Immunity 41, 1077-1083.

DAFFÉ, M. (1991). Further stereochemical studies on phthiocerol and phenolphthiocerol. Research in Microbiology 142, 405-410.

DafFé, M. \& LANÉElLE, M. A. (1988). Distribution of phthiocerol diester, phenolic mycosides and related compounds in mycobacteria. Journal of General Microbiology 134, 2049-2055.

DAFFE, M. \& SER VIN, P. (1989). Scalar, dipolar-correlated and Jresolved 2D-NMR spectroscopy of the specific phenolic mycoside of Mycobacterium tuberculosis. European Journal of Biochemistry 185, 157-162

Daffé, M., LanÉzlle, M.-A., Asselineau, C., Lévy-Frébault, V. \& DAVID, H. L. (1983). Intérêt taxonomique des acides gras des mycobactéries: proposition d'une méthode d'analyse. Annales de l'Institut Pasteur Microbiology 134B, 241-256.

Daffe, M., Lanéelle, M.-A., Roussel, J. \& Asselineau, C. (1984). Lipides spécifiques de Mycobacterium ulcerans. Annales de l'Institut Pasteur Microbiology 135A, 191-201. 
Daffé, M., Lacave, C., Lanéelle, M.-A. \& Lanéelle, G. (1987). Structure of the major triglycosylphenolphthiocerol of Mycobacterium tuberculosis (strain Canetti). European Journal of Biochemistry $167,155-160$

Daffé, M., Lanéelle, M.-A., Lacave, C. \& Lanéelle, G. (1988) Monoglycosyldiacylphenolphthiocerol of Mycobacterium tuberculosis and Mycobacterium bovis. Biochimica et Biophysica Acta 958, 443449.

DafFÉ, M., PAPA, F., LASZlo, A. \& David, H. L. (1989). Glycolipids of recent clinical isolates of Mycobacterium tuberculosis: chemical characterization and immunoreactivity. Journal of General Microbiology 135, 2759-2766.

Daffé, M., Cho, S.-N., Brennan, P. J. \& Chatterjee, D. (1991a). Chemical synthesis and seroreactivity of a neoantigen containing the oligosaccharide hapten of the Mycobacterium tuberculosis-specific phenolic glycolipid. Journal of Infectious Diseases 163, 161-168.

Daffé, M., Lanéelle, M.-A. \& Lacave, C. (1991b). Structure and stereochemistry of mycolic acids of Mycobacterium marinum and Mycobacterium ulcerans. Research in Microbiology 142, 397-403.

Dobson, G., Minnikin, D. E., Besra, G. S., Mallet, A. I. \& MAGNUSSON, M. (1990). Characterization of phenolic glycolipids from Mycobacterium marinum. Biochimica et Biophysica Acta 1042. 176-181.

Gastambide-Odier, M. \& Sarda, P. (1970). Contribution à l'étude de la structure et de la biosynthèse de glycolipides spécifiques isolés de mycobactéries: les mycosides A et B. Pneumology 142, 241-255.

Gerwig, G. J., Kamerling, J. P. \& Vliegenthart, F. G. (1978) Determination of the $D$ and $L$ configuration of neutral monosaccharides by high-resolution capillary GLC. Carbohydrate Research 62 , 349-357.

Gilleron, M., Venisse, A., Fournié, J.-J., Riviere, M., Dupont, M. A., Gas, N. \& Puzo, G. (1990). Structural and immunological properties of the phenolic glycolipids from Mycobacterium gastri and Mycobacterium kansasii. European Journal of Biochemistry 189, 167 173.

Haverkamp, J., De Bie, M. J. A. \& Vliegenthart, F. G. (1975). ${ }^{13} \mathrm{C}$ and 'H-NMR spectroscopy of permethylated gluco-, galacto-, and manno-pyranoses and their 6-deoxy analogues. Carbohydrate Research 39, 201-211.

HaYman, J. (1984). Mycobacterium ulcerans: an infection from the Jurassic time? The Lancet 1015-1016.

IMAEDA, T., BRoslawSKI, G. \& IMAEDA, S. (1988). Genomic relatedness among mycobacterial species by nonisotopic blot hybridization. International Journal of Systematic Bacteriology 38, 151-156.

Kasai, R., Okihara, M., Asakawa, J., Mizutani, K. \& Tanaka, O. (1979). ${ }^{13} \mathrm{C}$-NMR study of $\alpha$ - and $\beta$-anomeric pairs of D-mannopyranosides and $\mathrm{L}$-rhamnopyranosides. Tetrahedron 35, 1427-1432.

Laffite, C., NguYen PhuOC Du, A.-M., WinTERnitz, F., WyLde, R. \& Pratviel-Sosa, F. (1978). Synthèse et étude RMN de disaccharides et trisaccharides dans la série du L-rhamnose. Carbohydrate Research 67, 91-103.

LÉvy-Frébault, V. \& Varnerot, A. (1989). Detection of phthiocerol derivatives in Mycobacterium ulcerans: a preliminary report. Acta Leprologica 7, supplement 1, 61-64.

LÉvy-Frébault, V., GoH, K. S. \& David, H. L. (1986). Mycolic acid analysis for clinical identification of Mycobacterium avium and related mycobacteria. Journal of Clinical Microbiology 24, 835839.

Lévy-Frébault, V., Daffé, M., Goh, K. S., lanéelle, M. A., AsselineAu, C. \& DAVID, H. L. (1983). Identification of Mycobacterium fortuitum and Mycobacterium chelonei. Journal of Clinical Microbiology 17, 744-752.

Lévy-Frébault, V., Pangon, B., Buré, A., Katlama, C., Marche, C. \& DAVID, H. L. (1987). Mycobacterium simiae and Mycobacterium avium-M. intracellulare mixed infection in Acquired Immune Deficiency Syndrome. Journal of Clinical Microbiology 25, 154-157. luquin, M., Ausina, V., lopez Calamorra, F., Belda, F., Garcia Barcelo, M., Celma, C. \& Prats, G. (1991). Evaluation of practical chromatographic procedures for identification of clinical isolates of mycobacteria. Journal of Clinical Microbiology 29, 120-130.

Maclennan, A. P., Randall, H. M. \& SMith, D. W. (1961). The occurrence of methyl ethers of rhamnose and fucose in specific glycolipids of certain mycobacteria. Biochemical Journal 80, 309-318.

Martin-Casabona, N., Gonzalez Fluente, T., ArCalis Arce, L., Otal Entraigas, J. \& Vidal Pla, R. (1989). Evaluation of a phenolglycolipid antigen (PGL-Tbl) from $M$. tuberculosis in the serodiagnosis of tuberculosis: comparison with PPD antigen. Acta Leprologica 7, supplement 1, 89-93.

Minnikin, D. E. (1982). Lipids: complex lipids, their chemistry, biosynthesis and roles. In The Biology of the Mycobacteria, vol. 1, pp. 95-184. Edited by C. Ratledge \& J. L. Stanford. London: Academic Press.

Minnikin, D. E. \& PolgaR, N. (1967). Studies relating to phthiocerol. Part VII. Phthiodiolone A. Journal of the Chemical Society Series C 803-807.

Minnikin, D. E., Minnikin, S. M., Parlett, J. H., Goodfellow, M. \& MAGNUSSON, M. (1984a). Mycolic acid patterns of some species of Mycobacterium. Archives of Microbiology 139, 225-231.

Minnikin, D. E., Parlett, J. H., Magnusson, M., Ridell, M. \& LIND, A. $(1984 b)$. Mycolic acid patterns of representatives of Mycobacterium bovis BCG. Journal of General Microbiology 130 , 2733-2736.

Navalkar, R. G., Wiegeshaus, E., Kondo, E., Kim, H. K. \& Smith, D. W. (1965). Mycoside G, a specific glycolipid in Mycobacterium marinum (balnei). Journal of Bacteriology 90, 262-265.

Papa, F., Riviere, M., Fournié, J. J., Puzo, G. \& David, H. L. (1987). Specificity of a phenolglycolipid (Mycoside A) immunoserum. Journal of Clinical Microbiology 25, 2270-2273.

Portakls, F. (1989). Epidémiologie des ulcères à Mycobacterium ulcerans. Annales de la Société Belge de Médecine Tropicale 69, 91-103.

Rogall, T., Wolters, J., Flohr, T. \& Böttger, E. C. (1990). Towards a phylogeny and definition of species at the molecular level within the genus Mycobacterium. International Journal of Systematic Bacteriology 40, 323-330.

SAUTON, B. (1912). Sur le nutrition minérale du bacilli tuberculeux. Comptes rendus de l'Academie des Sciences (Paris) 155, 860-863.

Torgal-Garcia, J., David, H. L. \& PaPA, F. (1988). Preliminary evaluation of Mycobacterium tuberculosis phenolglycolipid antigen in the serologic diagnosis of tuberculosis. Annales de Microbiologie l'Institut Pasteur Microbiology 139, 289-294.

Villé, C. \& GASTAMBide-Odier, M. (1970). Le 3-O-méthyl-Lrhamnose, sucre du mycoside $G$ de Mycobacterium marinum. Carbohydrate Research 12, 97-107.

VERCELLONE, A.\& PUZo, G. (1989). New-found phenolic glycolipids in Mycobacterium bovis BCG. Presence of a diglycosylated glycolipid. Journal of Biological Chemistry 264, 7447-7454.

Vercellone, A., Riviere, M., Fournié, J. J. \& Puzo, G. (1988). Structural analogy between the major phenolic glycolipid antigens from two mycobacteria species: kansasii and gastri. Chemistry and Physics of Lipids 48, 129-134.

WAYNE, L. G. \& KUBICA, G. P. (1986). Genus Mycobacterium Lehmann and Neuman 1896, 363AL. In Bergey's Manual of Systematic Bacteriology, vol. 2, pp. 1436-1457. Edited by P. H. A. Sneath, N. S. Mair, M. E. Sharpe \& J. G. Holt. Baltimore: Williams and Wilkins.

Young, D. B. \& Buchanan, T. M. (1983). A serological test for leprosy with a glycolipid specific for Mycobacterium leprae. Science 221, 1057-1059.

Yu, R. K., Koerner, T. A. W., Scardale, J. N. \& Prestegard, J. H. (1986). Elucidation of glycolipid structure by proton nuclear magnetic resonance spectroscopy. Chemistry and Physics of Lipids 42 , 27-48. 